\title{
Modulation in Electric Conduction of PVK and Ferrocene-Doped PVK Thin Films
}

\author{
Hari Chandra Nayak ${ }^{1}$, Shivendra Singh Parmar ${ }^{2}$, Rajendra Prasad Kumhar ${ }^{1}$ and Shailendra Rajput ${ }^{3, *(D)}$ \\ 1 Department of Physics, Maharaja Chhatrasal Bundelkhand University, Chhatarpur 471001, India; \\ drhc.nayak@mp.gov.in (H.C.N.); drrajendrap.kumhar@mp.gov.in (R.P.K.) \\ 2 Department of Chemistry, Faculty of Sciences, Shri Krishna University, Chhatarpur 471001, India; \\ shivendraparmarofficial@gmail.com \\ 3 Department of Electrical and Electronic Engineering, Ariel University, Ariel 40700, Israel \\ * Correspondence: shailendrara@ariel.ac.il
}

Citation: Nayak, H.C.; Parmar, S.S.; Kumhar, R.P.; Rajput, S. Modulation in Electric Conduction of PVK and Ferrocene-Doped PVK Thin Films. Electron. Mater. 2022, 3, 53-62. https://doi.org/10.3390/ electronicmat3010005

Received: 30 November 2021

Accepted: 12 January 2022

Published: 14 January 2022

Publisher's Note: MDPI stays neutral with regard to jurisdictional claims in published maps and institutional affiliations.

Copyright: () 2022 by the authors Licensee MDPI, Basel, Switzerland. This article is an open access article distributed under the terms and conditions of the Creative Commons Attribution (CC BY) license (https:// creativecommons.org/licenses/by/ $4.0 /)$.

\begin{abstract}
In this article, the dielectric properties of poly (9-vinylcarbazole) (PVK) and ferrocene-doped PVK thin films are studied. The thin films were grown by the isothermal solution casting technique. Dielectric properties of grown films were studied as function of ferrocene concentration, frequency, and temperature. The relative permittivity $\left(\varepsilon^{\prime}\right)$ is increased with increasing ferrocene percentage $(\sim 1 \%)$ due to the free charge carriers. The relative permittivity decreases for higher ferrocene percentage $(\sim 2 \%)$. However, the relative permittivity of PVK and ferrocene-doped PVK samples remains almost constant for studied temperature range $(313-413 \mathrm{~K})$. The frequency dependence of $\tan \delta$ for all samples is studied. The frequency dependence of dielectric parameter exhibits frequency dispersion behavior, which suggests all types of polarization present in the lower frequency range. The loss $\operatorname{tangent}(\tan \delta)$ values are larger at higher temperatures in the low frequency region. However, the tan $\delta$ values at different temperatures are almost similar in the high frequency region. It is observed that the relative permittivity is maximum, dielectric loss is minimum, and AC conductivity is minimum for $1 \%$ ferrocene doped PVK as compared to pure PVK and $2 \%$ ferrocene doped PVK samples.
\end{abstract}

Keywords: poly (N-vinylcarbazole); activation energy; conduction mechanisms; ferrocene

\section{Introduction}

It is widely known that the polymers are useful for the growth of state-of-the-art economical devices. Researcher's growing interest in polymers in electronics is widely defensible by notable advantages in manufacturing of electro-optic devices, such as photovoltaic cells, polymeric field effect transistors, and polymeric light emitting diodes [1-3].

The poly (N-vinyl carbazole) (PVK) is a well-known hole transport polymer; therefore, this material is suitable for clarifying the effect of the injected holes on the breakdown process in polymer thin film [4]. The PVK has outstanding physicochemical properties such as high refractive index, photo-refractive, photoconductive, etc. Thus, PVK-based materials are applicable for several applications (e.g., photovoltaic cell and holograms photocopies) [5-7]. It was also reported that the nanocomposites consisting of inorganic nanoparticles and organic polymers (PVK) often exhibit far superior properties (mechanical, electrical, optical, and magnetic) than that of PVK [8,9]. Tang et al. studied the properties of PVK and proposed that PVK can be applicable as a high-potential organic polymer cathode for dual-intercalation Na-ion batteries [10]. Electrochemical, optical, and morphological properties of PVK prepared by electrochemical polymerization were studied by Bouriche et al. [11]. Studies on electroluminescence properties of pure PVK were recommended that the PVK is an excellent host material for phosphorescent polymer light-emitting diodes [12-14]. Frequency-dependent dielectric breakdown in the PVK thin films was also studied by several researchers $[15,16]$. 
Knowledge of dielectric behavior of the PVK materials is important because it throws light on several inside activities, for example-movement of dipoles, losses of energy, segmental motion, latent heat, conduction mechanism, etc. For device applications, the effect of injected carriers owing to the accumulation of electronic or ionic charges would become much more important. These charges significantly affect electrical conduction and breakdown.

In this work, dielectric properties of pure PVK and ferrocene doped PVK thin films are studied. The isothermal solution casting technique is employed for the preparation of thin films. Dielectric properties of grown thin films are measured and analyzed in order to optimize the ferrocene doping concentration.

\section{Materials and Methods}

Thin films of pure PVK and ferrocene doped were grown by the isothermal solution casting technique. The pure and ferrocene-doped PVK is soluble in chloroform, dichloromethane, dioxan, Dichlorobenzene, and pyridine. The solvent for synthesis of thin film was prepared using chloroform (AR-Grade) (Merck, New York, NY, USA). The concentration of solution is strongly affected the film thickness. Initially, $100 \mathrm{mg}$ of PVK was dissolved in $2 \mathrm{~mL}$ chemically pure chloroform. The solution was placed in glass beaker and was continuously stirred for $30 \mathrm{~min}$ with magnetic stirrer at room temperature. After that, the solution was heated up to $40{ }^{\circ} \mathrm{C}$ in order to find a uniform solution. For maximum dispersion, solution was stirred at a constant temperature approximately for $2-3 \mathrm{~h}$. The substrate (optically flat glass plate) was carefully cleaned using hot water and acetone. The PVK solution was poured uniformly on the substrate and. The substrate was placed in a mercury pool to achieve perfect and uniform film thickness [17]. Later, the samples were heated at constant temperature of $40{ }^{\circ} \mathrm{C}$ in dust free chamber. The samples were subjected to dry for $12 \mathrm{~h}$ at constant $40{ }^{\circ} \mathrm{C}$ temperature. The samples were left at room temperature for another $12 \mathrm{~h}$ to remove traces of solvent. Synthesis process of PVK thin film are demonstrated by schematic diagram In Figure 1.

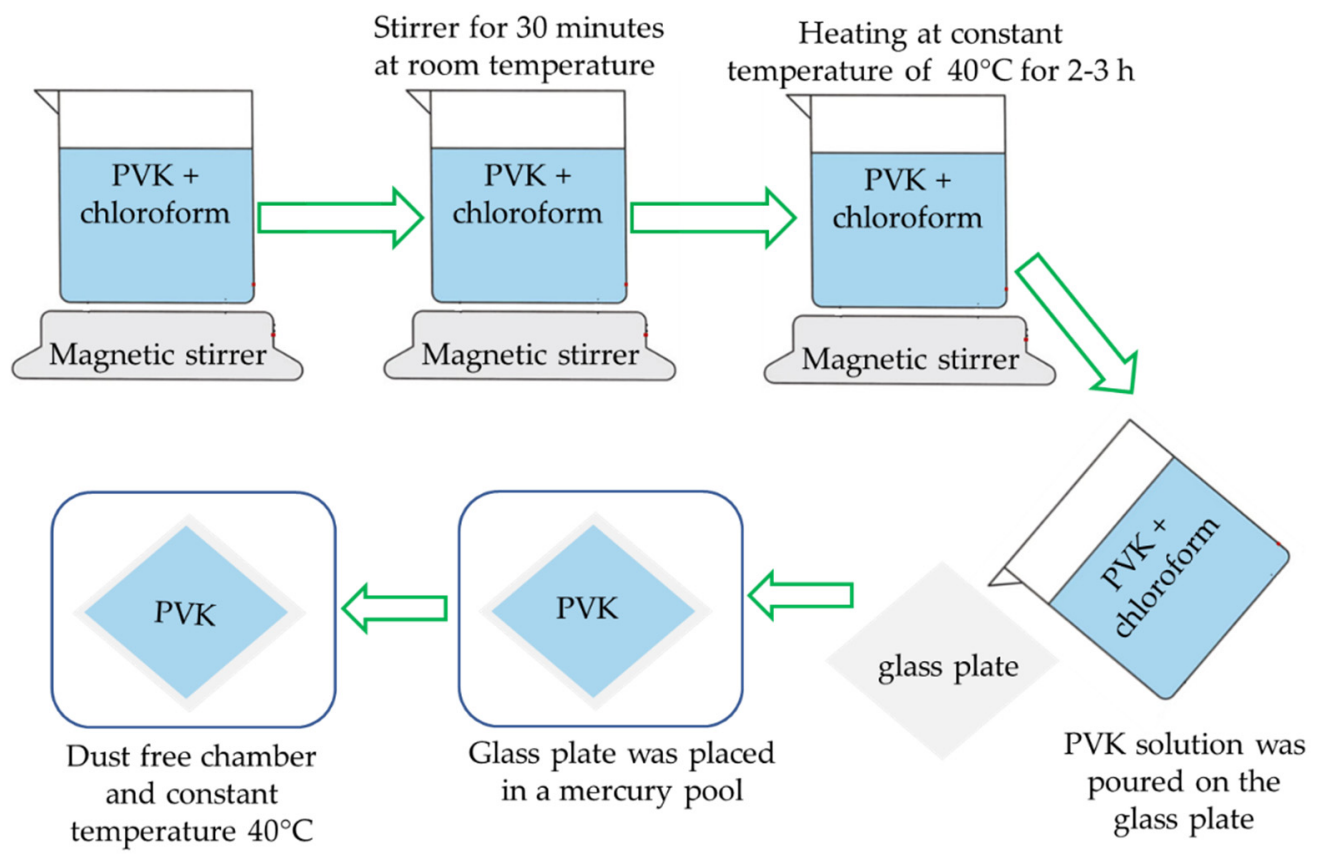

Figure 1. Schematic diagram of the thin film synthesis process.

In order to obtain pinhole free and smooth film, precaution was taken to reduce the rate of vaporization, because solvent chloroform has high rate of vaporization. Therefore, whole assembly (tray filled with mercury and solution poured glass plate) was partially covered with another glass plate. This resulted in slow vaporization rate of chloroform 
solvent and after some time a smooth pinhole free uniform thin film was obtained. Finally, the film was removed from glass plate. It was cut into small pieces of suitable size, which were washed with ethyl alcohol to remove the surface impurities and the dried films were ready for different studies.

The dielectric constant $\left(\varepsilon^{\prime}\right)$, dielectric loss $\left(\varepsilon^{\prime \prime}\right)$, loss tangent $(\tan \delta)$, Capacity $(\mathrm{C})$, acconductivity $\left(\sigma_{a c}\right)$ of grown thin films were measured as a function of frequency and temperature using a computer-controlled LCR Hi-Tester (HIOKI 3520, HIOKI E.E. corporation, Nagano, Japan). The instrument can perform measurement in two modes, first one is measurements of impedance $(Z)$ and phase angle $(\delta)$, while the second one is capacitance (C) and loss factor (D). The temperature of the samples was varied at the uniform rate of $10{ }^{\circ} \mathrm{C} / \mathrm{min}$. The temperature was measured with thermocouple (J-type, Thermo Sensors Co., Nagpur, India). To measure dielectric parameters, the silver paste was applied on both the flat surfaces of thin films. After that, the samples were heated at $100{ }^{\circ} \mathrm{C}$ for $3 \mathrm{~h}$ to remove moisture.

\section{Results and Discussion}

\subsection{Relative Permittivity}

Figure 2a-c demonstrates the relative permittivity-frequency curves of pure, $1 \%$, and $2 \%$ ferrocene doped PVK samples in the frequency range $1 \mathrm{~Hz}-1 \mathrm{MHz}$ and at different temperatures (313-413 K). It is observed that the $\varepsilon^{\prime}$ values are decreased sharply, as the frequency increases. An intermediate plateau is observed between lower and higher frequencies in case of PVK and 1\% ferrocene doped PVK samples. All curves show similar exponentially decreasing trends at different temperatures as a function of the logarithm of angular frequency. The same behavior is obtained for pure and doped samples of PVK.

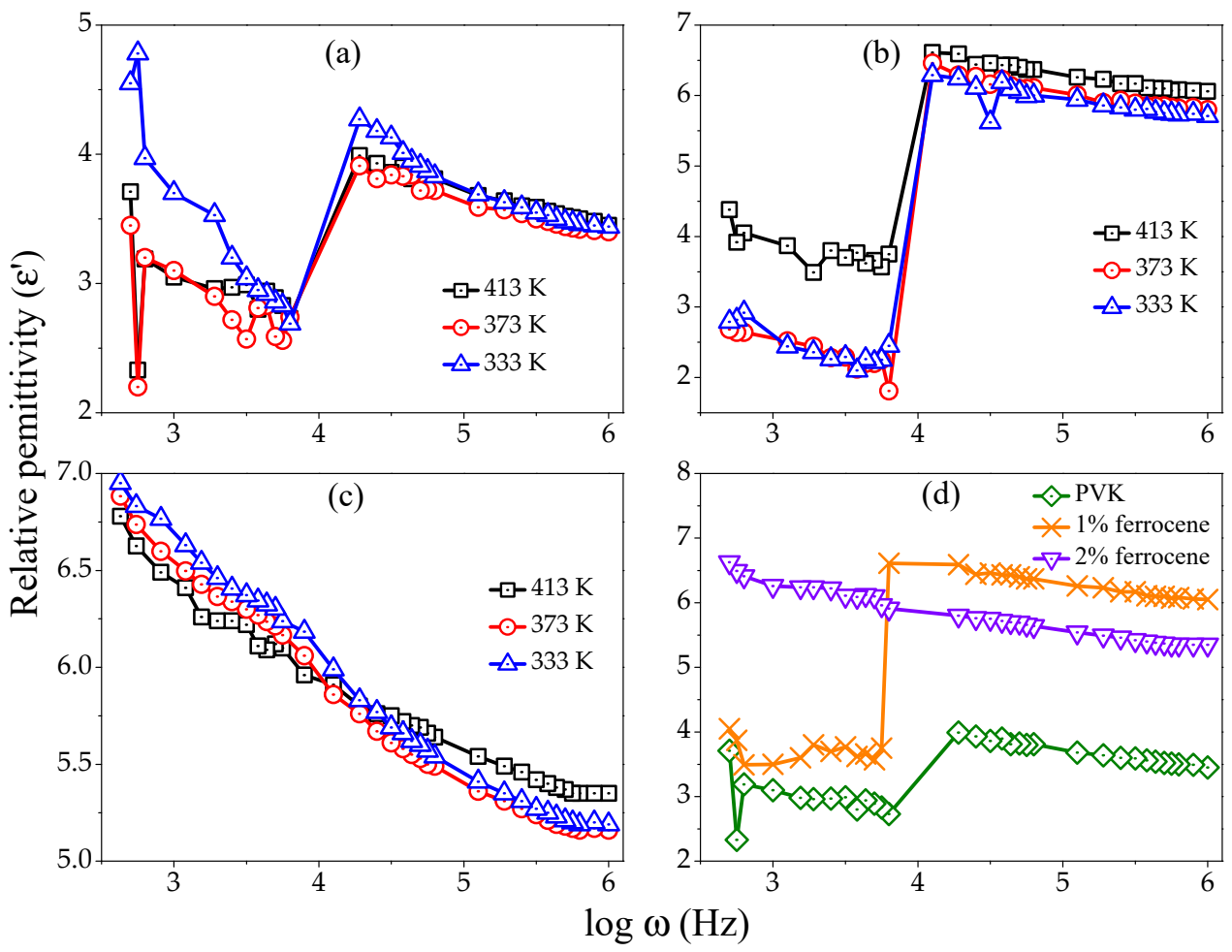

Figure 2. Variation of real part of dielectric constant $\left(\varepsilon^{\prime}\right)$ as function of frequency for (a) pure PVK, (b) $1 \%$ ferrocene doped PVK, (c) $2 \%$ ferrocene doped PVK, and (d) at $413 \mathrm{~K}$ for pure and doped PVK.

The observed behavior of $\varepsilon^{\prime}$ can be ascribed to the fact that the dipoles orient in the direction of the applied field at low frequencies. At higher frequencies, the dipoles are unable to rotate swiftly. As a result, the oscillations of dipoles lag behind as compared to the field. The dipoles are completely unable to follow the field at more higher frequencies. 
Thus, all slow polarizations are ended, and the $\varepsilon^{\prime}$ archives constant value due to the interfacial polarization only [18]. Another reason for the decrease in $\varepsilon^{\prime}$ values could be the decreased polarization ascribed to charge accumulation. The theory of Dissado and Hill also explains this behavior, that a single cluster dipole moment relaxation takes place at high frequency [19]. The Jonscher's power law $\left(\varepsilon^{\prime} \propto f^{n-1}\right.$, where $\left.0<n<1\right)$ can also explain the behavior of $\varepsilon^{\prime}$ at higher frequencies [20].

In doped samples, the free charge carriers are generated at sample interfaces and contributed to the ionic conductivity enhancement. The amount of accumulated charge enhances due to the polarization of the polymer/metal interfaces. The polarization sums up an extra role to the charge quantity. Therefore, the $\varepsilon^{\prime}$ values of the doped samples ( $1 \%$ ferrocene doped) are higher than the pure polymer [21]. This explanation is proven by the experimental results of the present study. Figure $2 \mathrm{~d}$ shows the $\varepsilon^{\prime}$ variation as a function of frequency for pure and doped PVK thin films at temperature of $413 \mathrm{~K}$. It is observed that the $\varepsilon^{\prime}$ value increases with ferrocene doping concentration up to $1 \%$. However, $\varepsilon$ ' value decreases for higher ferrocene doping concentration (2\%). It can be concluded that the $1 \%$ ferrocene doping in PVK is critical doping concentration. The change in the tendency of curve from $1 \%$ doped PVK to $2 \%$ ferrocene doped PVK is definitely not due to any major structural phase transformation, as the ferrocene has a good thermal stability up to $400{ }^{\circ} \mathrm{C}$ [22]. In addition, the electropolymerization in PVK may result crosslinked polycarbazole units, and it can be implemented as both hole injection layer and hole transport layer $[23,24]$. Moreover, the cyclopentadienyl ring in ferrocene is partially negatively charged and is susceptible to electrophilic substitution reaction [25]. Therefore, it is easy to introduce a donor group to ferrocene. This indicates that there is a possibility of formation of network-like structure by the crosslinking of ferrocene and PVK. With the increase in ferrocene percentage in PVK, the number of free dipole units at the interfacial region decreases due to polymerization. Thus, the interfacial contribution at low frequency range minimal resulting a different trend in permittivity curve.

Figure $3 \mathrm{a}-\mathrm{c}$ exhibits the temperature dependence (313-413 K) of $\varepsilon^{\prime}$ at different frequencies for pure, $1 \%$, and $2 \%$ ferrocene doped PVK, respectively. It is seen that the $\varepsilon^{\prime}$ increases as the temperature increases at lower frequencies and decreases at higher frequencies. The comparative $\varepsilon^{\prime}$ variation as a function of temperature for pure and doped PVK at frequency $100 \mathrm{kHz}$ is shown in Figure $3 \mathrm{~d}$. It is observed that the $\varepsilon^{\prime}$ value increases with doping concentration as a function of temperature. The temperature dependence of $\varepsilon^{\prime}$, representing the decreasing trends initially for all samples at low temperature 313 to $353 \mathrm{~K}$, maybe due to the existence of water molecules in the samples. At high temperatures 353 to $413 \mathrm{~K}, \varepsilon^{\prime}$ sharply increases. The decrease in $\varepsilon^{\prime}$ with temperature can be attributed to the fact that dipoles in polar are unable to orient themselves at lower temperatures. However, the orientation of dipoles is facilitated as the temperature is raised. Thus, orientational polarization increases and contributes to the increase in $\varepsilon^{\prime}$.

\subsection{Dielectric Loss}

Figure $4 \mathrm{a}-\mathrm{c}$ represents the loss factor versus $\log$ frequency for pure, $1 \%$, and $2 \%$ ferrocene doped PVK samples at different temperatures (313-413 K). The behavior of $\tan \delta$ values are typical of polymeric materials. The dispersion is widespread and broader than that expected by the Debye theory with a distribution of relaxation times. The second high-frequency region reveals the polarization of numerous dipoles. The figures depict the relation between $\tan \delta\left(=\frac{\varepsilon^{\prime \prime}}{\varepsilon^{\prime}}\right)$ and $\log (f)$. 


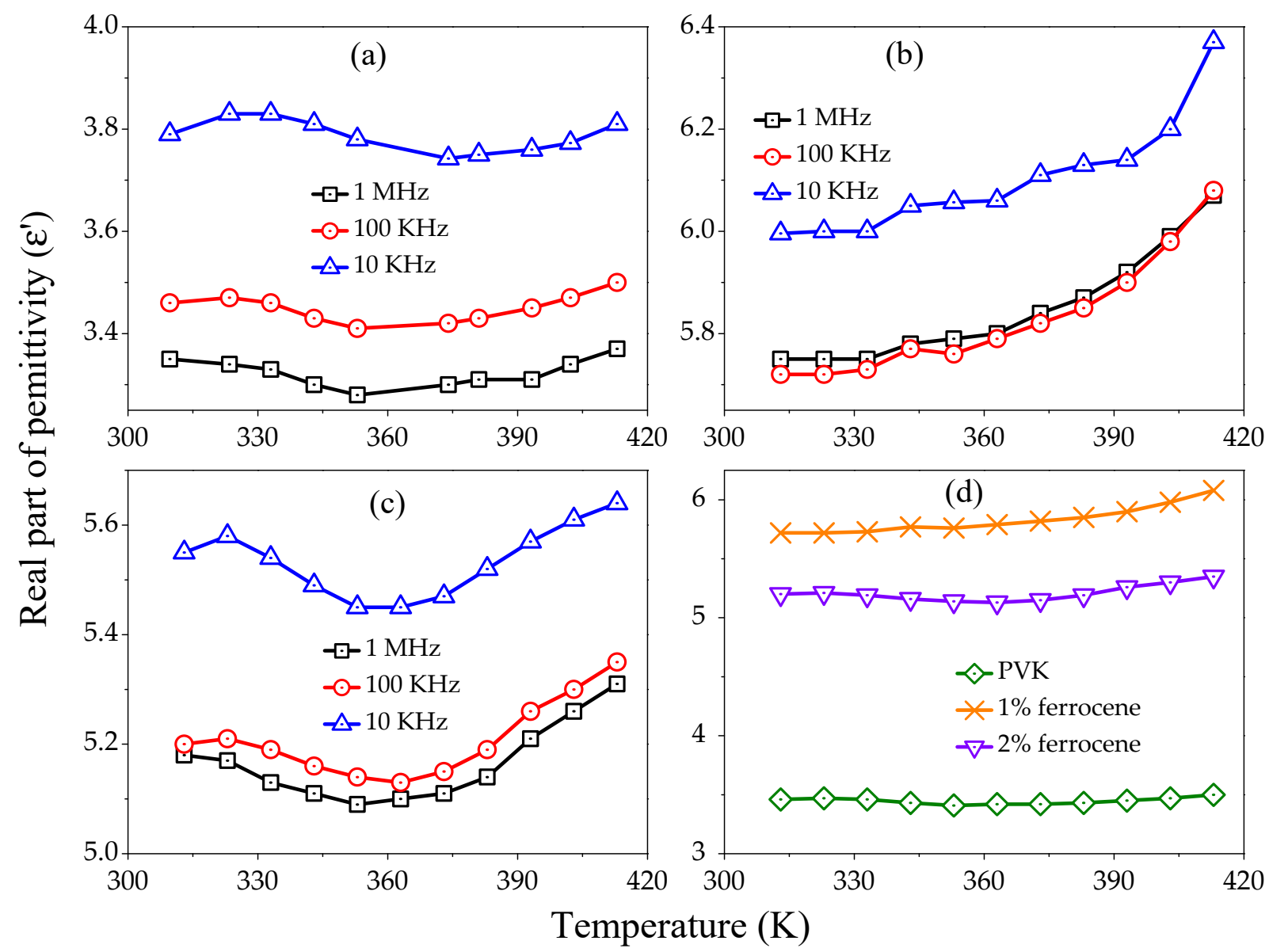

Figure 3. Variation of real part of dielectric constant $\left(\varepsilon^{\prime}\right)$ as function of temperature for (a) pure PVK, (b) $1 \%$ ferrocene doped PVK, (c) $2 \%$ ferrocene doped PVK, and (d) at frequency of $100 \mathrm{kHz}$ for pure and doped PVKs.

It is observed that the $\tan \delta$ decreases exponentially with the frequency upsurge for all studied temperatures. It can be seen from figures that the $\tan \delta$ values are larger at higher temperatures in the low frequency region. However, the $\tan \delta$ values at different temperatures are almost similar in the high frequency region. These figures are also representing frequency dominant relaxation. Figure $4 \mathrm{~d}$ shows that the comparison between $\tan \delta$ values of PVK and ferrocene doped PVK thin films.

Figure $5 \mathrm{a}-\mathrm{c}$ represents the tangent loss variation versus temperature for pure, $1 \%$ and $2 \%$ ferrocene doped PVK samples at several frequencies $(1 \mathrm{MHz}, 100 \mathrm{kHz}$, and $10 \mathrm{kHz})$. All curves show, increase in loss tangent with temperature but record decrease with increasing frequencies. Figure $5 \mathrm{~d}$ shows a comparative loss tangent as a function of temperature for pure and ferrocene doped PVK at $100 \mathrm{kHz}$ frequency. The decreased $\tan \delta$ values with frequency show the reduced number of charges and delay in dipoles settling due to very short time availability (one-half cycle of alternating voltage). The other probability may be the interfacial polarization of injected and included charges at the crystalline-amorphous interface. The polymers usually have loss factors of less than 0.1 at temperatures well below glass transition temperature $\left(T_{g}\right)[26]$. 

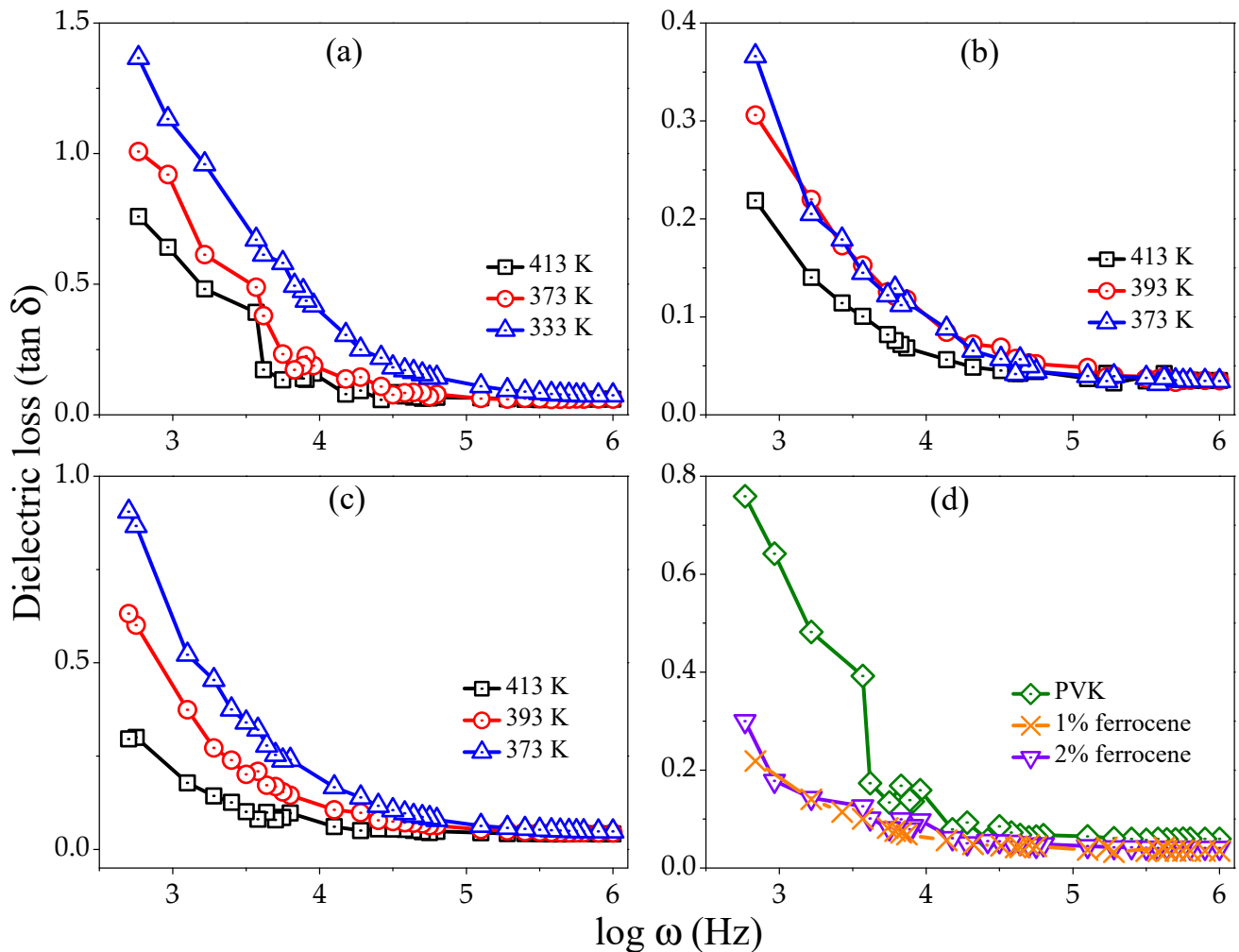

Figure 4. Variation of real part of loss tangent $(\tan \delta)$ as function of frequency for (a) pure PVK, (b) $1 \%$ ferrocene doped PVK, (c) 2\% ferrocene doped PVK, and (d) at $413 \mathrm{~K}$ for pure and doped PVK.

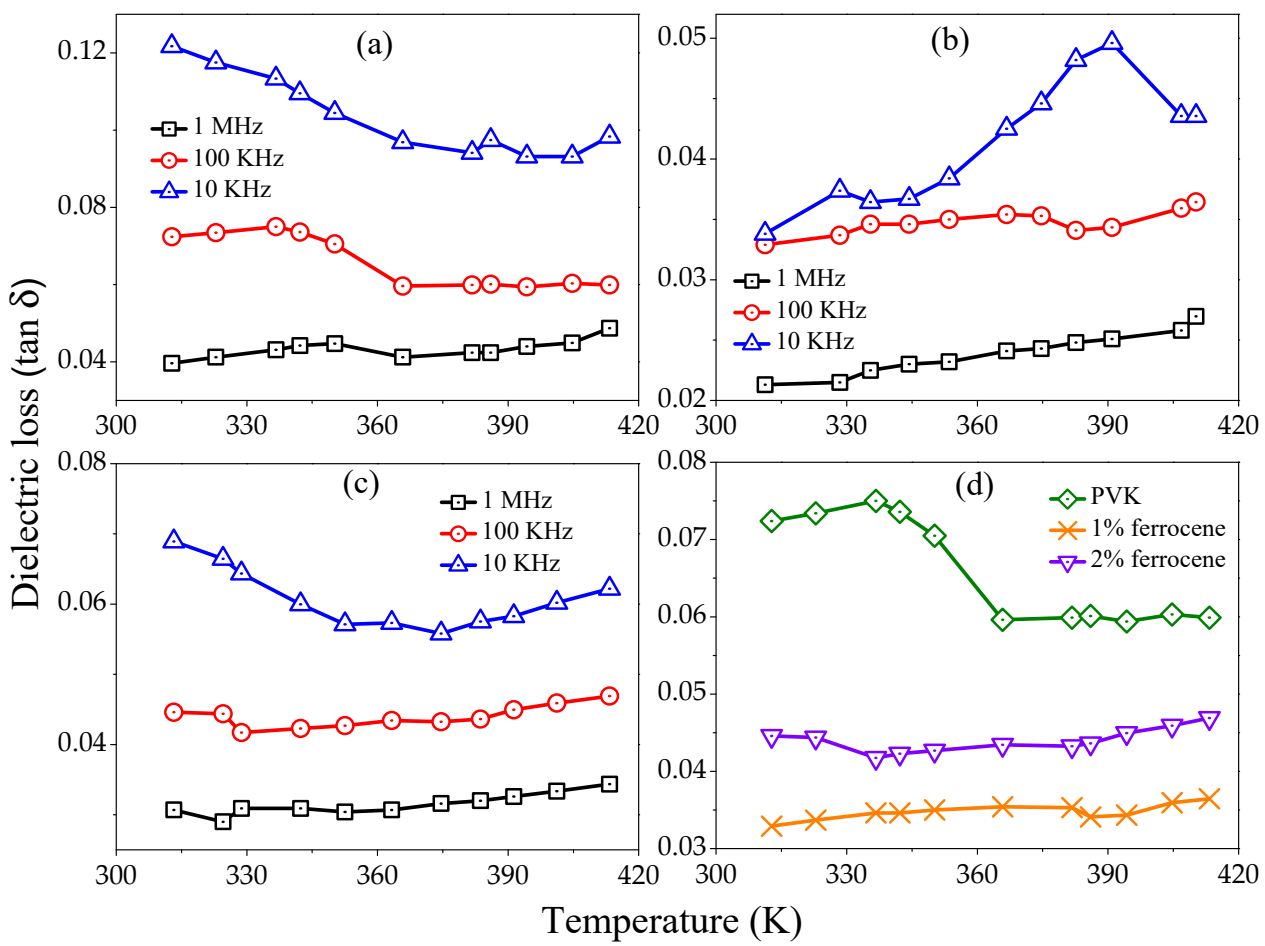

Figure 5. Variation of real part of loss tangent $(\tan \delta)$ as function of temperature for (a) pure PVK, (b) $1 \%$ ferrocene doped PVK, (c) 2\% ferrocene doped PVK, and (d) at frequency of $100 \mathrm{kHz}$ for pure and doped PVKs. 


\subsection{AC-Conductivity}

Figure 6a-c shows the relationship between ac conductivity $\left(\sigma_{a c}\right)$ and of frequency at different temperatures ( 313 to $413 \mathrm{~K}$ ) for pure, $1 \%$, and $2 \%$ ferrocene doped PVK, respectively. It is found that conductivity increases as frequency increases at fixed temperatures and pronounced dispersion has been observed at lower frequencies. All curves of $\log \sigma_{a c}$ versus $\log \omega$ show approximately similar nature of increasing trends. Figure $6 \mathrm{~d}$ shows the comparative variation of $\sigma_{a c}$ as a function of frequency for pure and doped PVK samples at temperature of $413 \mathrm{~K}$. The $\sigma_{a c}$ value increases with increasing ferrocene concentration. It is presumed that an electrically conducting path and network could be molded in the doped samples by increasing fillers' concentration [22]. An AC field of sufficiently high frequency may cause a net out of phase polarization. This results in an increase in conductivity at a higher frequency.
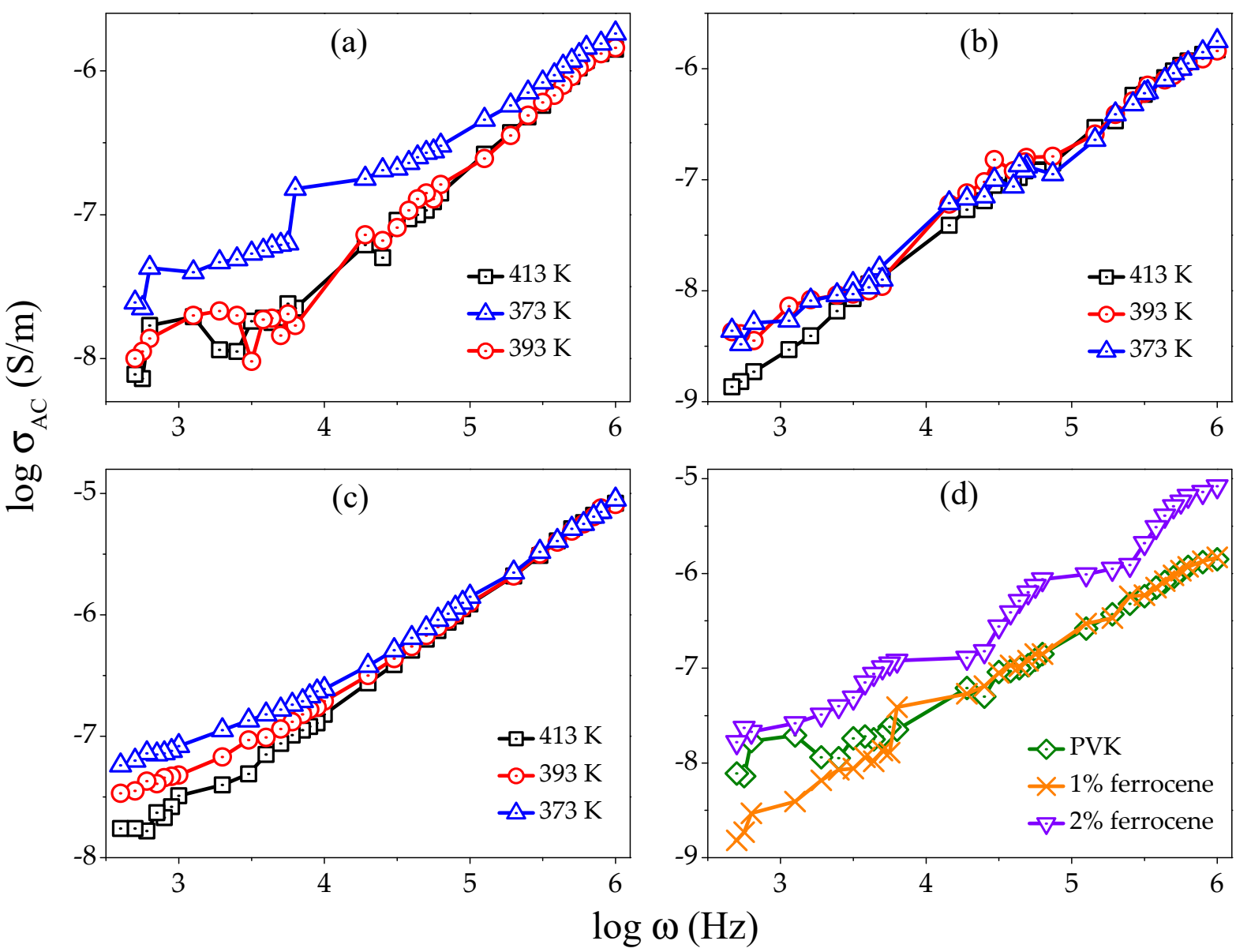

Figure 6. Variation of ac-conductivity as function of frequency for (a) pure PVK, (b) $1 \%$ ferrocene doped PVK, (c) 2\% ferrocene doped PVK, and (d) comparison of AC conductivity of PVK and doped PVK at 373.

The frequency dependent conductivity behavior at constant temperature is investigated on the basis of on the power relation proposed by Jonscher [20].

$$
\sigma(\omega)=\sigma(0)+A \omega^{n}
$$

where $\sigma(\omega)$ is the total conductivity, $\sigma(0)$ the frequency-independent conductivity, i.e., $\sigma_{d c}$, and $A$ depends on temperature. In the lower frequency region, the exponent $n$ rises with the increase in temperature. The value of $n$ varies in the range 1.5 to 2 and in the range 0.1 and 0.5 for lower and higher frequency regions, respectively. The value of $\sigma_{a c}$ increases with the $n$ the ferrocene doping may be ascribed to the surface morphology and consistent 
dispersion of the ferrocene in the PVK matrix, which improves charge conduction at the polymer-ferrocene interface.

Figure $7 \mathrm{a}-\mathrm{c}$ shows the variation of $\sigma_{a c}$ with the temperature at various fixed frequencies $(1 \mathrm{MHz}, 100 \mathrm{kHz}$, and $10 \mathrm{kHz}$ ) for pure, $1 \%$ and $2 \%$ ferrocene doped PVK. It is observed that the $\sigma_{a c}$ values for all samples are larger at higher frequencies. Figure $7 \mathrm{~d}$ shows the variation of $\sigma_{a c}$ as a function of temperature for pure and ferrocene doped PVK samples at fixed frequency $100 \mathrm{kHz}$. It is also clear from figures that magnitude of $\sigma_{a c}$ increases as temperature increase from $313 \mathrm{~K}$ to $413 \mathrm{~K}$. However, the effect of frequency on $\sigma_{a c}$ is significantly less at higher temperatures. It can be concluded that the conductivity of studied samples is bulk limited or field-dependent, mostly at lower temperature regions.

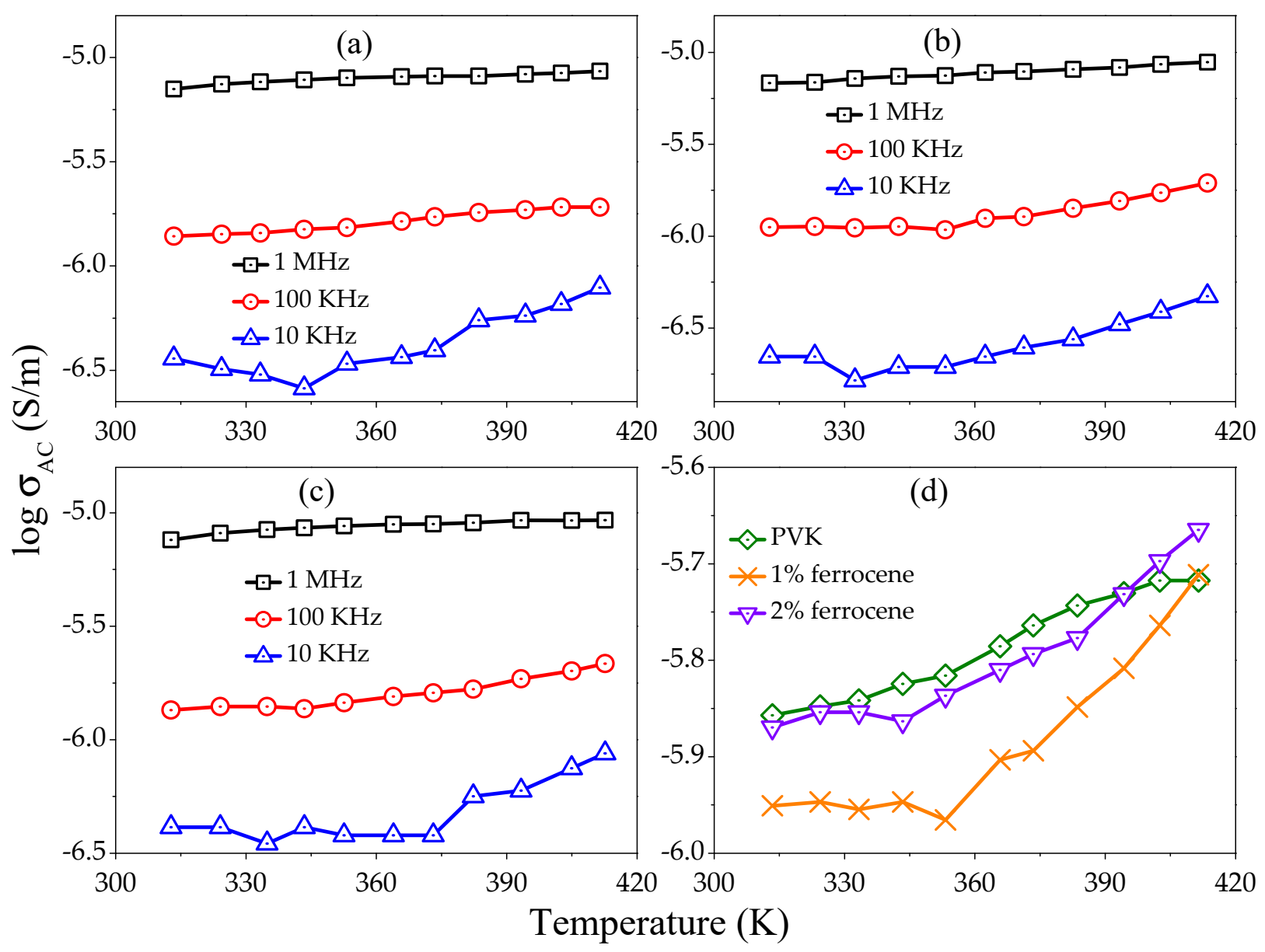

Figure 7. Relationship between AC conductivity and temperature at different frequencies in case of (a) pure PVK, (b) 1\% ferrocene doped PVK, (c) 2\% ferrocene doped PVK, and (d) comparison of AC conductivity of PVK and doped PVK at frequency of $100 \mathrm{kHz}$.

The increase in $\sigma_{a c}$ may be associated with the increase in relative permittivity for the ferrocene doped PVK thin films. In doped samples, occurrence of newer complexes may be ascribed to the enhanced $\varepsilon^{\prime}$ as well as $\sigma_{a c}$. The introduction of localized states can be responsible for increased conductivity on ferrocene doping. The ferrocene molecules can diffuse strongly in the polymer structure due to the smaller molecular size. Moreover, it is claimed that the ferrocene addition creates extra hopping sites for the charge carriers and henceforth upsurge the conductivity (Figure 7d).

\section{Conclusions}

In summary, pure and ferrocene doped PVK thin films are successfully prepared using the isothermal solution casting technique. The dielectric parameter exhibits frequency 
dispersion behavior, which suggests all types of polarization present in the lower frequency range. It is observed that the $\varepsilon^{\prime}$ is maximum, $\tan \delta$ is minimum, and $\sigma_{a c}$ is minimum for $1 \%$ ferrocene doped PVK than that of pure PVK and $2 \%$ ferrocene doped PVK thin films. Hence, it can be concluded that the $\sim 1 \%$ ferrocene is the critical doping point for PVK. The influence of temperature on the $\varepsilon^{\prime}, \tan \delta$, and $\sigma_{a c}$ is not very significant over the investigated temperature range ( 313 to $413 \mathrm{~K}$ ). The temperature effect is more pronounced in the low-frequency region. The conductivity of PVK is increased as the ferrocene dopant concentration of increases up to $2 \%$. The higher conductivity is related to the additional hopping sites for the charge carriers.

\begin{abstract}
Author Contributions: Conceptualization, H.C.N. and S.R.; methodology, H.C.N., S.S.P. and R.P.K.; validation, H.C.N., S.S.P. and R.P.K.; formal analysis, H.C.N. and S.R.; investigation, H.C.N., S.S.P. and R.P.K.; resources, H.C.N., S.S.P. and R.P.K.; data curation, H.C.N., S.S.P. and R.P.K.; writingoriginal draft preparation, H.C.N. and S.S.P.; writing-review and editing, S.R.; supervision, project administration, and funding acquisition, H.C.N. and S.R. All authors have read and agreed to the published version of the manuscript.
\end{abstract}

Funding: This research received no external funding.

Institutional Review Board Statement: Not applicable.

Informed Consent Statement: Not applicable.

Data Availability Statement: The data presented in this study are available on request from the corresponding author.

Conflicts of Interest: The authors declare no conflict of interest.

\title{
References
}

1. Mbarek, M.; Sagaama, L.; Alimi, K. New copolymer involving PVK and F8BT for organic solar cells applications: Design, synthesis, characterization and theoretical studies. Opt. Mater. 2019, 91, 447-454. [CrossRef]

2. Gustafsson, G.; Cao, Y.; Treacy, G.M.; Klavetter, F.; Colaneri, N.; Heeger, A.J. Flexible light-emitting diodes made from soluble conducting polymers. Nature 1992, 357, 477-479. [CrossRef]

3. Mbarek, M.; Almoneef, M.M.; ben Saleh, Y.; Alimi, K. Organic optoelectronic copolymer involving PVK and F8T2: Synthesis and characterization. Spectrochim. Acta A Mol. Biomol. Spectrosc. 2021, 252, 119509. [CrossRef] [PubMed]

4. Nakagawa, K.; Ishida, Y. Dielectric relaxations and molecular motions in poly (vinylidene fluoride) with crystal form II. J. Polym. Sci. Polym. Phys. Ed. 1973, 11, 1503-1533. [CrossRef]

5. Jamal, M.; Sarac, A.S.; Magner, E. Conductive copolymer-modified carbon fibre microelectrodes: Electrode characterisation and electrochemical detection of p-aminophenol. Sens. Actuators B Chem. 2004, 97, 59-66. [CrossRef]

6. Li, T.; Fukuyama, H.; Yamagata, Y.; Lan, H.L.; Kido, J. Organic electroluminescent devices using europium complex-doped poly (N-vinylcarbazole). Polym. Adv. Technol. 2004, 15, 302-305. [CrossRef]

7. Li, B.Z.; Tamada, M.; Koshikawa, H.; Kimura, Y.; Suwa, T.; Seguchi, T. Radiation polymerization of N-vinylcarbazole and electroluminescent behavior of poly (N-vinylcarbazole). Polymer 2000, 41, 7043-7049. [CrossRef]

8. Kumari, S.; Kushwah, K.K.; Dubey, S.; Ramrakhiani, M. Studies on CdSe/PVK nanocomposites films for electroluminescent display applications. Opt. Mater. 2019, 97, 109319. [CrossRef]

9. Wang, S.; Yang, S.; Yang, C.; Li, Z.; Wang, J.; Ge, W. Poly (N-vinylcarbazole)(PVK) photoconductivity enhancement induced by doping with CdS nanocrystals through chemical hybridization. J. Phys. Chem. B 2000, 104, 11853-11858. [CrossRef]

10. Tang, W.; He, H.; Shi, J.; Cao, B.; Yang, C.; Fan, C. Poly (N-vinylcarbazole)(PVK) as a high-potential organic polymer cathode for dual-intercalation Na-ion batteries. Org. Electron. 2019, 75, 105386. [CrossRef]

11. Bouriche, O.; Bouzerafa, B.; Kouadri, H. Electrochemical, optical and morphological properties of poly (N-vinylcarbazole/TiO2) and (N-vinylcarbazole/aniline)/ $\mathrm{TiO}_{2}$ copolymer prepared by electrochemical polymerization. e-Polymers 2018, 18, 111-122. [CrossRef]

12. Ye, T.; Chen, J.; Ma, D. Electroluminescence of poly (N-vinylcarbazole) films: Fluorescence, phosphorescence and electromers. Phys. Chem. Chem. Phys. 2010, 12, 15410-15413. [CrossRef] [PubMed]

13. Song, M.; Park, J.S.; Kim, C.H.; Im, M.J.; Kim, J.S.; Gal, Y.S.; Kang, J.W.; Lee, J.W.; Jin, S.H. High efficiency, solution-processed, red phosphorescent organic light-emitting diodes from a polymer doped with iridium complexes. Org. Electron. 2009, 10, 1412-1415. [CrossRef]

14. Qian, L.; Bera, D.; Holloway, P.H. Effects of ultraviolet light irradiation on poly (vinlycarbazole). Appl. Phys. Lett. 2008, 92, 31. [CrossRef] 
15. Miyairi, K. Frequency-dependent dielectric breakdown in thin polyvinylcarbazole films. Jpn. J. Appl. Phys. 2003, $42,5153$. [CrossRef]

16. Clergereaux, R.; Seguy, I.; Jolinat, P.; Farenc, J.; Destruel, P. Electronic conduction in electropolymerized carbazole thin films. J. Phys. D Appl. Phys. 2000, 33, 1947. [CrossRef]

17. Shah, S.; Singh, D.; Qureshi, A.; Singh, N.L.; Singh, K.P.; Shrinet, V. Dielectric properties and surface morphology of proton irradiated ferric oxalate dispersed PVC films. Indian J. Pure Appl. Phys. 2008, 46, 439-442.

18. Saha, S.; Sinha, T.P. Dielectric relaxation in $\mathrm{SrFe}_{1 / 2} \mathrm{Nb}_{1 / 2} \mathrm{O}_{3}$. J. Appl. Phys. 2006, 99, 014109. [CrossRef]

19. Dissado, L.A.; Hill, R.M. Anomalous low-frequency dispersion. Near direct current conductivity in disordered low-dimensional materials. J. Chem. Soc. Faraday Trans. 2 Mol. Chem. Phys. 1984, 80, 291-319. [CrossRef]

20. Ngai, K.L.; Jonscher, A.K.; White, C.T. On the origin of the universal dielectric response in condensed matter. Nature 1979, 277, 185-189. [CrossRef]

21. Dweck, J.; Andrade, B.; Monteiro, E.; Fischer, R. Thermal characterization of polymeric plaster composites. J. Therm. Anal. Calorim. 2002, 67, 321-326. [CrossRef]

22. Didier, A. Why is Ferrocene so Exceptional? Eur. J. Inorg. Chem. 2017, 2017, 6-29.

23. Jegadesan, S.; Advincula, R.C.; Valiyaveettil, S. Nanolithographic electropolymerization of a precursor polymer film to form conducting nanopatterns. Adv. Mater. 2005, 17, 1282-1285. [CrossRef]

24. Baba, A.; Onishi, K.; Knoll, W.; Advincula, R.C. Investigating Work Function Tunable Hole-Injection/Transport Layers of Electrodeposited Polycarbazole Network Thin Films. J. Phys. Chem. B 2004, 108, 18949-18955. [CrossRef]

25. Dai, L.X.; Tu, T.; You, S.L.; Deng, W.P.; Hou, X.L. Asymmetric Catalysis with Chiral Ferrocene Ligands. Acc. Chem. Res. 2003, 36, 659-667. [CrossRef]

26. Dang, Z.M.; Zhang, Y.H.; Tjong, S.C. Dependence of dielectric behavior on the physical property of fillers in the polymer-matrix composites. Synth. Met. 2004, 146, 79-84. [CrossRef] 